\section{Military Technical College Kobry El-Kobbah, Cairo, Egypt.}

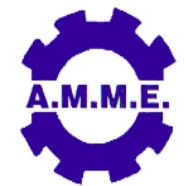

\section{$18^{\text {th }}$ International Conference on Applied Mechanics and Mechanical Engineering.}

\title{
INTRODUCTION TO SYSTEMS ENGINEERING
}

\author{
S. Wiriadidjaja ${ }^{1}$, F. Hasim², G. Wibisono ${ }^{3}$ and R. Rusyadi ${ }^{4}$
}

\begin{abstract}
Systems engineering is an interdisciplinary approach and means to enable the realization of successful systems. It is also considered as the art and science of developing an operable system that meets requirements within often opposed constraints. Systems engineering is a holistic, integrative discipline, wherein the contributions of aerospace engineers, electrical engineers, mechatronic engineers, physics engineers, structural engineers, and many more disciplines are evaluated and balanced, one against another, to produce a coherent whole that is not dominated by the perspective of a single discipline. In fact, systems engineering integrates all the disciplines and specialty groups into a team effort forming a structured development covering a system life cycle, which is commonly used to refer to the stepwise, iterative evolution of a new system from "cradle to the grave", i.e., from concept through development and on to production, operation, and ultimate disposal.
\end{abstract}

The recognition of systems engineering as a distinct activity is often associated with the effects of the $2^{\text {nd }}$ World War. Thereafter, systems engineering has evolved from a process focused primarily on large-scale and complex defense systems to a broader discipline that is used in all kinds of project development. Indeed, systems engineering principles can be applied to any system development.

Research and development efforts, on the other-hand, have typically avoided application of structured processes according to systems engineering principles, primarily due to a perception that such structure inhibits the creative processes that are so crucial to the discovery and development of new technologies. Systems engineering principles and creative discovery are, however, not mutually exclusive environments. In the contrary, appropriately tailored systems engineering processes may enable and enhance scientific discovery.

In this contribution, the principles and practices of systems engineering will be introduced. Some emphasis is to be given to systems development process, which includes the system life cycle model with its evolutionary characteristics, and the use of the so-called systems engineering method.

Through a few case studies, the viewpoints of systems engineering principles will be described. Regarding the scientific discovery, the application of the same principles, including the risk management, to basic research, applied research and development research will be presented. The future state of systems engineering will also be highlighted.

\section{KEYWORDS}

complex, engineering, interdisciplinary, iterative, life cycle, systems

1 Chief executive officer, Engsyspro Inc., Indonesia, and Senior Member of the American Institute for Aeronautics and Astronautics (AIAA). Email: suriatin@engsyspro.com.

2 Senior engineer, Center of Technology for Defense and Security Industries, Governmental Agency for Assessment and Application of Technology (BPPT), Indonesia. Email: fadilah.hasim@bppt.go.id.

3 Managing director, Engsyspro Inc., Indonesia, Email: gunawan@engsyspro.com.

4 Senior lecturer, Swiss German University, Indonesia, Email: rusman.rusyadi@sgu.ac.id. 